\title{
Design and development of a novel centrifuge ablative pyrolysis approach for biomass conversion to bio-oil and bio-char
}

\author{
Murlidhar Gupta*, Andrew McFarlan, Leslie Nguyen and Fernando Preto, \\ Natural Resources Canada, CanmetENERGY, 1 Haanel Drive, Ottawa, Ontario K1A 1M1, Canada
}

\begin{abstract}
Pyrolysis has evolved as a key pre-treatment step to produce renewable fuels and chemicals from agricultural and forestry residues. In the past few years, there have been different directions in the development of pyrolysis reactors. For example, in vortex and cyclone approaches, biomass particles are suspended in a flow of high supersonic velocities to ensure enough centrifugal forces for pressing the particles against the heated reactor surface. Although simple in design, the requirement of large volumes of carrier gases necessitates cumbersome downstream gas separation, resulting in thermodynamic penalties and higher capital equipment costs. In ablative systems, with little or no carrier gases, the key challenge relates to using an appropriate mechanism to continuously apply forces on biomass particles during pyrolysis. In a recent alternative approach, thermo-mechanical rotors at very high rpm have been used to create the required centrifugal forces for pressing the biomass particles against the heated walls of a concentric shell. In the current approach, a modular centrifuge pyrolysis system has been designed using Biot and Thiele numbers as key constraints for characterizing ablative regimes. Unlike other centrifuge pyrolysis reactors, the novel rotor mechanism incorporated in this reactor system facilitates constant centrifugal force as well continuous propagation of biomass feeds. The $10 \mathrm{~kg} / \mathrm{hr}$ thermomechanical pyrolysis system has been successfully commissioned using hardwood sawdust. Properties of bio-oil and bio-char produced in this new reactor have been compared to products from fluid bed pyrolysis system. In addition to its compact and modular design suitable for mobile pyrolysis units, it can be operated in variable regimes of pyrolysis, e.g., slow to fast modes, allowing adjustable product distribution.
\end{abstract}

\section{Introduction}

Thermochemical conversion of solid biomass residues is considered as a potential pathway for generation of renewable heat and power, as well as value added chemicals. Combustion, gasification and pyrolysis, which vary in degrees of oxidation, are key steps for thermochemical conversion. Unlike combustion processes, pyrolysis is an endothermic

\footnotetext{
*Corresponding author: Murlidhar.Gupta@,Canada.ca
} 
thermochemical process and carries some similarity with conventional crude distillation process. In pyrolysis, biomass is heated in absence of any oxidant (air or oxygen) between 400-600 ${ }^{\circ} \mathrm{C}$ to decompose complex biomass molecules, producing solid (bio-char), pyrolysis liquids and gaseous streams (please see Fig.1). These liquids are mixtures of highly oxygenated organic compounds. Although polar and nearly immiscible with conventional crude oil fractions, these pyrolysis liquids are widely referred to as bio-oil because they have the potential to be converted into transportation fuels.

Heat transfer rates play an important role for qualitative and quantitative distribution of solid and liquid yields in pyrolysis processes. Depending upon the heating rates of the biomass particles and the residence time of the vapours, many reactor configurations have been proposed for fast pyrolysis in the last few decades [1,2]. These configurations include shallow moving beds or transported beds (vacuum pyrolysis), auger reactors, fluid beds and ablative reactors.

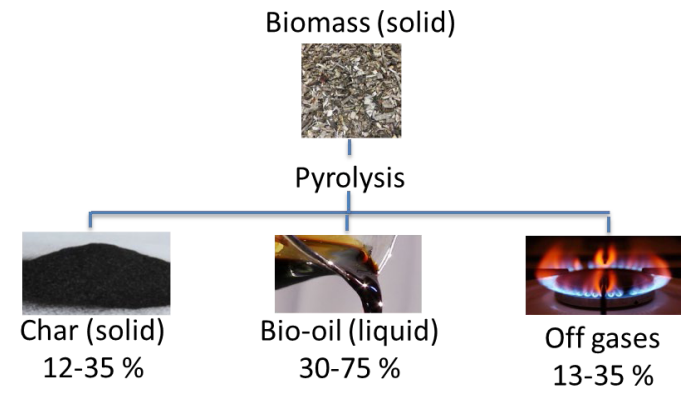

Fig. 1 Distribution of solid, liquid and gaseous streams in biomass pyrolysis

In moving bed vacuum pyrolysis reactors, the high heating rates are achieved by indirect heat transfer in moving beds through a high temperature molten salt loop and reduced residence time is achieved by pulling out the pyrolysis vapours under vacuum for quick quenching $[1,2]$. While moving bed pyrolysis processes are capable of handling large particle size distribution and a wide range of feedstocks including plastics and waste tires, the indirect heat transfer and vacuum are the limiting factors in developing a compact moving bed vacuum pyrolysis unit.

In fluid bed fast pyrolysis reactors, the high heat transfer rates are achieved by increasing surface area through reducing biomass feedstocks to very small particle size and transferring the heat through direct exposure to a heat carrier such as hot fluidizing gas (e.g., nitrogen) and heated sand particles. Although some fluid bed pyrolysis reactors have reached demonstration scale, the designs carry inherent requirements of very small particle size (1-3 mm) which increases the milling costs and energy consumption. In addition, the process requires large volumes of carrier gas to be heated, cooled and separated for recycle causing inherent thermodynamic penalties.

In the ablative pyrolysis process, a biomass particle is pressed against a hot surface while the particle moves relative to the heating surface. Due to rapid surface renewal of biomass particles, very high heat transfer rates can be achieved [3]. Since the pyrolysis reaction rates are primarily controlled by the heat transfer mechanisms, the ablative process facilitates rapid pyrolysis of large biomass particles.

In the past few years, there have been different directions in development of ablative reactors. In the vortex and cyclone approaches, biomass particles are suspended in a flow at supersonic velocities to ensure enough centrifugal forces for pressing the particles against the heated reactor surface [1-3]. Although simple in design, the main problem with these reactors is their requirement of large volumes of carrier gas relative to biomass feed which 
escalates cost due to cumbersome gas separation and resultant thermodynamic penalties $[2,4,5]$.

\section{Challenges in design and operation of ablative reactor with low or negligible carrier gas}

The key challenge relates to using appropriate mechanisms to apply the required force on small and large biomass particles in a continuous ablative pyrolysis reactor, with no or minimal use of a carrier gas. Such ablative reactors would be quite compact and well-suited as mobile pyrolysers, because they process large amounts of biomass with small volumetric footprints.

Bridgewater et al. 2009 used a rotating metal blade to directly press the biomass particles against a heated cylinder [5], whereas, in their pursuit for continuous ablation, Bech et al 2009 used a thermo-mechanical rotor at very high rpm to create centrifugal forces for pressing the biomass particles against the heated walls of a concentric shell [4]. This design used radial blades and spirally twisted flow guide rings welded on the inner surface of the heated reactor wall, for providing continuous centrifugal force and forward motion of the particles. In order to prevent accumulation of unconverted biomass/bio-char inside the reactor, the inner wall of the reactor shell was welded with spirally twisted flow guide rings. Welding of these kinds of guiding rings on the reactor wall is difficult to fabricate and it is difficult to maintain their integrity in a continuous pyrolysis process. If the particle size of the feed changes, the guiding rings need to be changed leading to an expensive and time-consuming process.

The objective of this work has been to design and develop a modular centrifuge ablative pyrolysis reactor, which does not use guiding rings and yet continuously produces pyrolysis product streams comparable to other fast pyrolysis processes, without any biomass or char accumulation in the reactor.

\section{Materials and Methods}

\subsection{Design approach}

Design approach uses dimensionless thermal Biot number, $B i$, and thermal Thiele number, Th. The Biot number is a relative measure of heat flux to particle surface and heat flux to interior of particle and is given by

$$
B i=\frac{h L_{0}}{\lambda}
$$

Where $L_{0}$ is the characteristic particle length and $\lambda$ is the particle thermal conductivity and $h$ is the external heat transfer coefficient further defined by

$$
h=\frac{1}{118(s+1)} d_{p} \rho g G
$$

Here, $d_{p}$ is the particle diameter, $r$ particle density, $G$ the dimensionless centrifugal acceleration and $g$ is the acceleration due to gravity. For spherical particles, $s=2$

The thermal Thiele number, Th, compares two characteristics times e.g. the heat penetration time and the reaction time and is given by

$$
T h=\frac{r_{p} L_{0}^{2} c_{p}}{\lambda}
$$

Where $c_{p}$ is the specific heat of biomass particles and $r_{p}$ is the rate of reaction at an average temperature of $500{ }^{\circ} \mathrm{C}$. 
To achieve the ablative regime in the reactor both $B i$ and $T h$ were ensured to be greater than one $[4,6]$. In order to provide continuous propagation and avoid any accumulation of biomass feed and residual char in the shell, a novel rotor design was incorporated into the pyrolysis reactor.

\subsection{Experimental}

A modular ablative centrifuge reactor with a design capacity of $10 \mathrm{~kg} / \mathrm{hr}$ biomass feed was fabricated and installed on two platforms (See Fig. 2). The upstream section which includes biomass feeder and ablative centrifuge reactor was installed in the upper floor (Mezzanine); see Fig. 2(a). The downstream section, which includes cyclones for solids removal, a direct contact pyrolysis vapours condenser, and gravity separator, was built on the lower platform. (See Fig.2b).
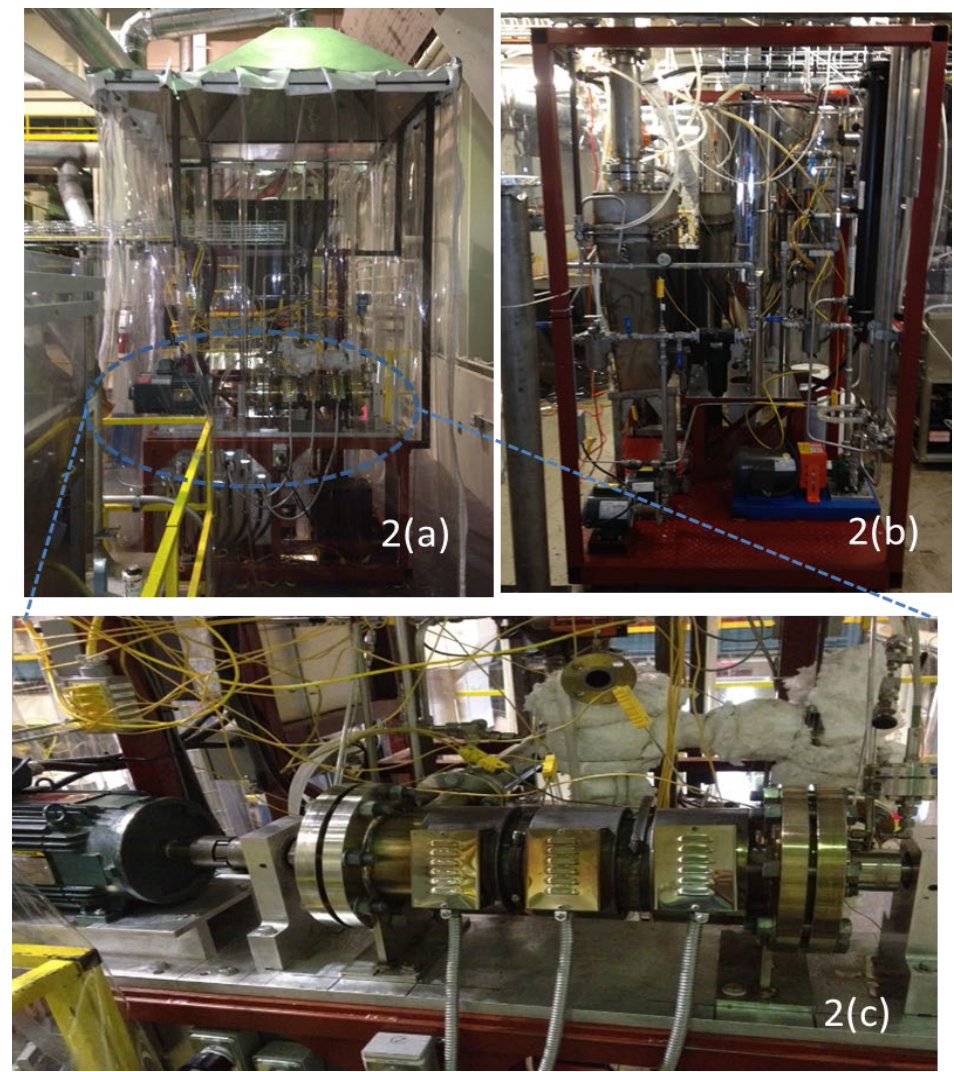

Fig. 2. CanmetENERGY's $10 \mathrm{~kg} / \mathrm{hr}$ pilot scale centrifuge pyrolysis reactor; 2(a) The upstream deck with biomass feeder and reactor; 2(b) The downstream with char separation and vapour handling; 2(c) Compact centrifuge ablative reactor.

The ablative reactor comprises a shell made of a $150 \mathrm{~mm}$ (nominal) diameter stainless steel pipe that is externally heated by three band heaters. Band heaters are controlled by temperature monitoring through their respective thermocouples and temperature controllers. The reactor shell houses a rotor whose axis of rotation is fixed by bearing blocks located on either side outside of the reactor housing. The rotor is coupled with a motor that allows the rotor to attain very high rotational speeds up to 10,000 RPM. Control of the motor is performed manually through a variable speed controller. The sealing of the reactor contents 
from the atmosphere is facilitated by high temperature oil seals within seal assemblies at either end of the reactor. To ensure seals were adequately protected, they were cooled with nitrogen, as well as with water. For hot commissioning experiments, hardwood sawdust was used as the feedstock of choice as the same feed was previously pyrolysed using a 10 $\mathrm{kg} / \mathrm{hr}$ fluid bed unit with similar balance of plant and this provided an opportunity to compare the products from the two reactor systems.

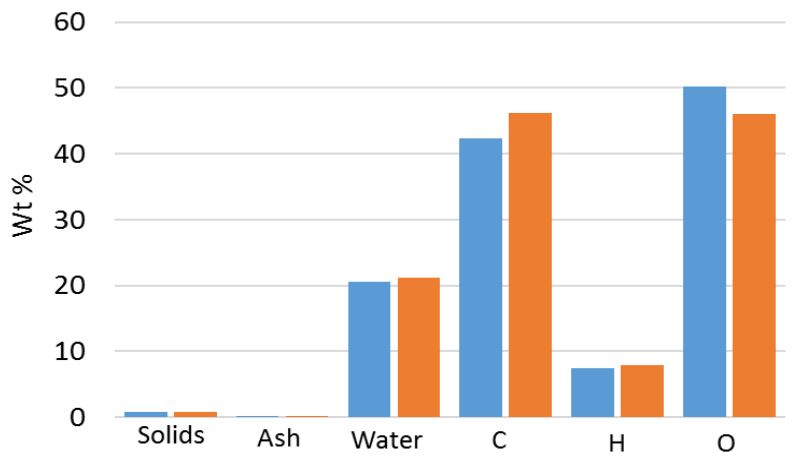

$$
1500
$$
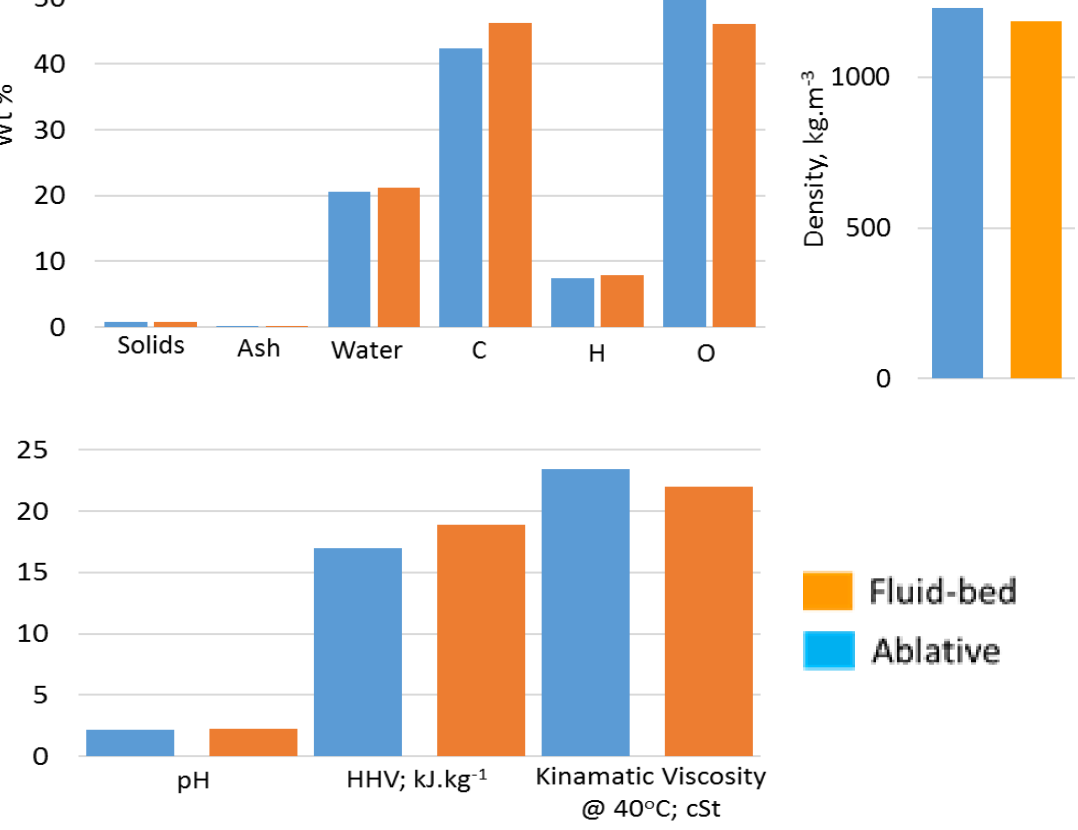

Fig. 3 Ultimate and proximate analysis of bio-oils obtained from ablative centrifuge fluid bed pyrolysis systems.

\section{Results and discussion}

Prior to the hot pyrolysis runs, fine cellulose powder was used in cold runs to assess the continuity of solid flow at different rotor speeds. The cold tests confirmed the mechanical performance of the reactor design and it attained rotor speeds up to 6500-rpm achieving centrifugal acceleration close to $3.5 \mathrm{G}$. This was achieved without any significant vibrations and without any clogging of flow inside the reactor and cyclone systems.

Subsequently, commissioning pyrolysis runs were carried at $500{ }^{\circ} \mathrm{C}$ with hardwood sawdust feedstock. The ablative centrifuge pyrolysis unit ran successfully at a rotor speed of $2000 \mathrm{rpm}$ without any noticeable vibrations and without any clogging of char inside the reactor system. During the hot run operations, the unit was able to maintain fast pyrolysis regime (vapour residence time of less than 2 seconds).

Figure 3 shows the ultimate analysis, density, HHV and kinematic viscosity of bio-oil obtained from the ablative centrifuge pyrolysis unit. These properties were compared with bio-oil produced in a fluid bed unit with the same hardwood sawdust feed and with similar capacity and balance of plant components except the reactor system. The results indicate that although the oxygen content of bio-oil from ablative centrifuge pyrolysis is around 5\% higher than fluid bed based system, other properties, e.g., $\mathrm{pH}, \mathrm{HHV}$, are nearly the same as 
for fluid bed reactors. The bio-oil samples from the ablative centrifuge pyrolysis system show approximately $8 \%$ less solid loading, which is an indication of less solid attrition in ablative process compared to fluid systems.
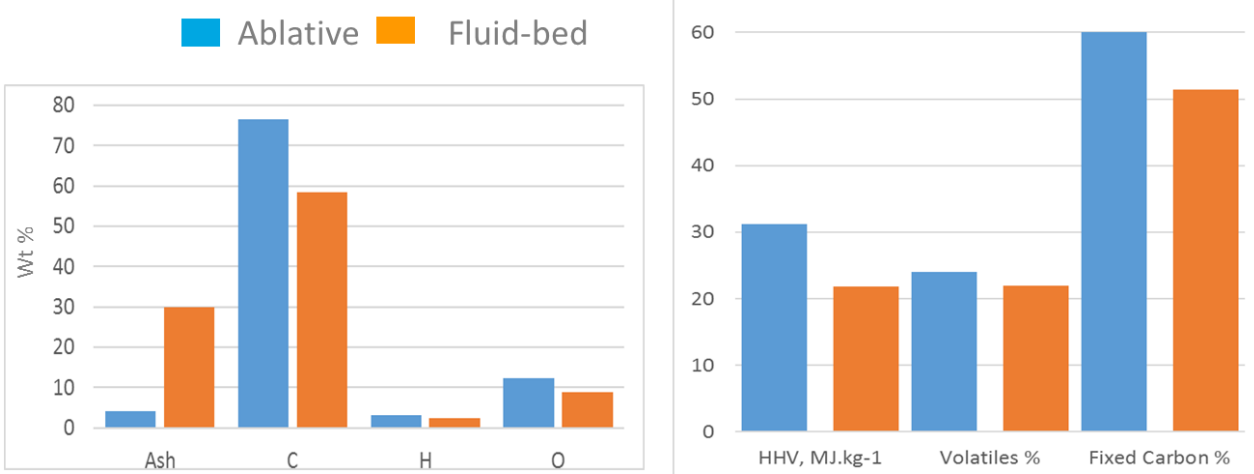

Fig. 4 Ultimate and proximate analysis of bio-chars o bed pyrolysis systems.

Figure 4 shows the HHV and ultimate analysis of bio-char samples captured at the two cyclones. When compared to bio-char obtained from fluid bed system, results show that ash content in the char from ablative pyrolysis is significantly lower at $4.25 \%$ compared to $29.8 \%$ in fluid bed system. Similarly, carbon and hydrogen content are also high providing nearly $43 \%$ higher heating value for ablative char compared to fluid bed system. Low ash, high fixed carbon and high heating values are desirable in many end use applications that include combustion and metallurgical cokes.

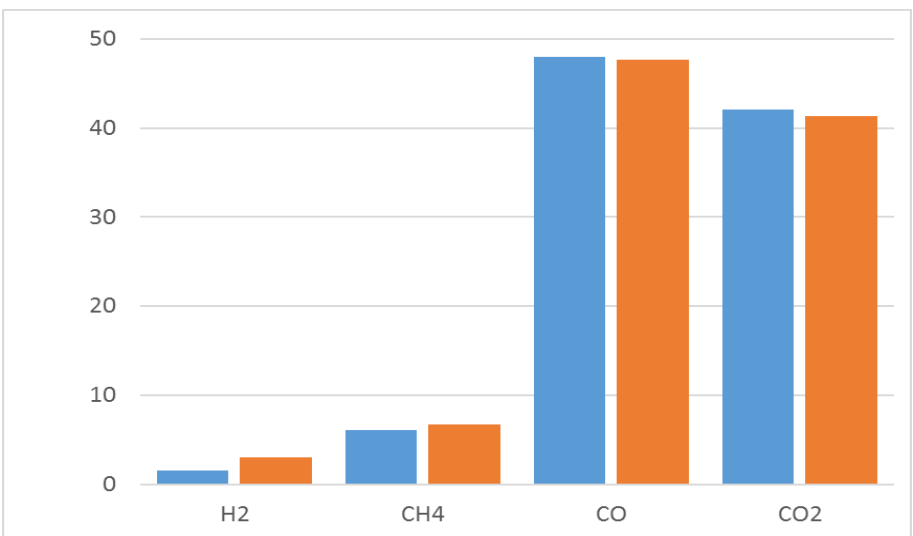

Fig. 5 Composition of off gases from ablative centrifuge and fluid bed pyrolysis systems.

Figure 5 shows the gas composition of non-condensable gases from ablative pyrolysis of hardwood sawdust on a nitrogen-free basis. When compared with fluid bed off gases, results indicate nearly same concentrations of $\mathrm{CO}$ and $\mathrm{CO}_{2}$, which accounts for approximately $90 \%$ of total off gases. The mass yield of off-gases for the ablative centrifuge and the fluid bed were also similar at 10.3 and $11.9 \%$, respectively. The concentration of $\mathrm{H}_{2}$ and $\mathrm{CH}_{4}$ from off gas samples in ablative pyrolysis unit are lower than fluid bed system by $47 \%$ and $8 \%$ respectively, but only account for less than $10 \%$ of total gases. 


\section{Conclusions}

The cold and hot runs proved that operational continuity of the ablative pyrolysis unit was not hindered by char build-up or clogging inside the reactor. Moreover, the majority of fine char particles exited from the centrifuge reactor to the two cyclones confirming the desired outcome of this novel rotor design.

Bio-oil, char and off gas samples obtained from ablative centrifuge system were compared with the fluid bed pyrolysis system. Results indicate that the product quality in ablative centrifuge system is comparable with other fast pyrolysis systems fed with similar feedstock and having the similar balance of plant components. Future plans include optimisation of unit with low quality forestry and agriculture residues.

Compared to existing state of the art, the novel design of this ablative centrifuge system is extremely simple and compact. Such thermochemical pyrolysers can be operated as distributed systems, under variable pyrolysis regimes ranging from slow to fast pyrolysis, and avoiding large quantities of carrier gas. Although scale up for large centralized pyrolysis plants may be an issue, these ablative centrifuge pyrolysis units can be adapted in a modular approach for large facilities.

Authors appreciate technical assistance from Karam Khosa, Ron Campbell, Sylvain Derome, Mitchell Noy, Benjamin Bronson, and Dillon Mazerolle. Authors acknowledge funding support from Panel of Energy Research and Development, Government of Canada. Authors also acknowledge suggestions from Dr. Peter Gogolek for improving the quality of this manuscript.

\section{References}

1. D. Mohan, C.U. Pittman and P.H. Steele, Energy \& Fuels, 20, 848-889 (2006)

2. D. Vamvuka, International Journal of Energy Research, 35(10), 835-862 (2010)

3. S. Scholl, H. Klaubert and D. Meier, Science in Thermal and Chemical Biomass Conversion, Edited by A.V. Bridgewater and D.G.B. Boocock, 2, 1372-1379 (2006)

4. N. Bech, M. Boberg Larsen, A.J. Jensen, K. Dam-Johansen, Biomass and Bioenergy 33, 999-1011 (2009)

5. A.V. Bridgewater, G.V.C. Peacocke and N.M. Robinson, Ablative thermolysis unit", US Patent No. US 7,625,532 B2, (2009).

6. A.V. Bridgwater and D.G.B. Boocock, Developments in Thermochemical Biomass Conversion, 1, ISBN 978-94-009-1559-6 (eBook); DOI 10.1007/978 94-009-1559-6; 1-1648, (1997) 